\title{
CHARACTERISTICS OF CHILD SAFETY SEAT USERS
}

\author{
Alexander C. WagenaAR, ${ }^{*}$ Lisa J. MolnaR* \\ and LEwIS H. MARGOLIS $\dagger$ \\ The University of Michigan, Transportation Research Institute* and School of Public Health, $\dagger$ \\ 2901 Baxter Road, Ann Arbor, MI 48109-2150, U.S.A.
}

(Received 18 May 1987; in revised form 2 November 1987)

\begin{abstract}
Direct observation of child restraint use was combined with interviews and mail questionnaires to measure prevalence of various child restraint practices and factors related to use of child safety seats and seat belts for children under the age of four. Trained observers assessed multiple dimensions of child restraint practices for a sample of motorists entering fastfood parking lots in Michigan. On-site interviews and follow-up questionnaires measured sociodemographic, attitudinal, belief, and behavioral characteristics related to restraint use. Ninetytwo percent of infants under age 1 and $55 \%$ of children age 1 to 3 were traveling in a child safety seat. Public support for the mandatory child restraint law was very high-9 out of 10 believed it should be strictly enforced. Child restraint use was lower than average among motorists who: (1) had low family incomes, (2) were not currently married, (3) were of nonwhite ethnic backgrounds, and (4) were over the age of 40 . A shift in social norms appears to have occurred in recent years, such that restraint of young children traveling in cars is now socially expected bchavior. Recommendations include: (1) continuing educational efforts to increase knowledge of mandatory child restraint use laws, and (2) increased enforcement of mandatory child restraint use laws.
\end{abstract}

\section{INTRODUCTION}

Motor vehicle crashes are the leading cause of death of American children once past infancy and are responsible for significant numbers of severe and often disabling injuries. The efficacy of child restraint devices (CRDs) and seat belts in preventing a substantial proportion of crash fatalities and injuries is well documented [Rutherford, Greenfield, and Hayes et al., 1985; Evans, 1986; Wagenaar and Webster, 1986; Evans and Frick, 986]. All 50 U.S. states have implemented laws requiring child restraint use. Although Michigan implemented such a law in April 1982, recent direct-observation surveys at a probability sample of 240 intersections throughout the state revealed that about onefourth of children under the age of four travel unrestrained [Wagenaar and Wiviott, .986].

Several studies of sociodemographic, behavioral, and other factors related to CRD use have appeared. The most frequent finding is that child restraint use is positively associated with the socioeconomic status of the parent or driver [Williams, 1972; NeuInann, Neumann, and Cockrell et al., 1974; Pless and Roghmann, 1978; Philpot, Heathington, and Perry et al., 1979; Kielhorn and Westphal, 1980; Jonah and Dawson, 1982; 'Nard and Clearie, 1982; Hletko, Hletko and Shelness et al., 1983; Faber and Hoppe, 1.984; Foss, 1985]. Other demographic characteristics reportedly associated with child restraint use include gender (female) [Kielhorn et al., 1980; Jonah et al., 1982; Faber et al., 1984], marital status (married) [Neumann et al., 1974; Philpot et al., 1979; Hletko 't al., 1983], and ethnic background (white) [Kielhorn et al., 1980; Jonah et al., 1982; Jaber et al., 1984]. Numerous studies have found child restraint use to be significantly related to belt use of parents [Williams, 1972; Neumann et al., 1974; Philpot et al., 1979; Hletko et al., 1983; Verreault, Stulginskas, and Keyl et al., 1982; Rood and Kraichy, 1986; Wagenaar, Wiviott, and Businski, 1986]. Protecting one's children when driving is related to other preventive health behaviors such as regular pediatric visits, regular dental visits, and not smoking [Kielhorn et al., 1980; Hletko et al., 1983]. Finally, Faber and Hoppe [1984] found that self-reported intentions to use child restraints are related to previous crash involvement; however, an earlier study by Neumann and others [1974] found no such relationship. 


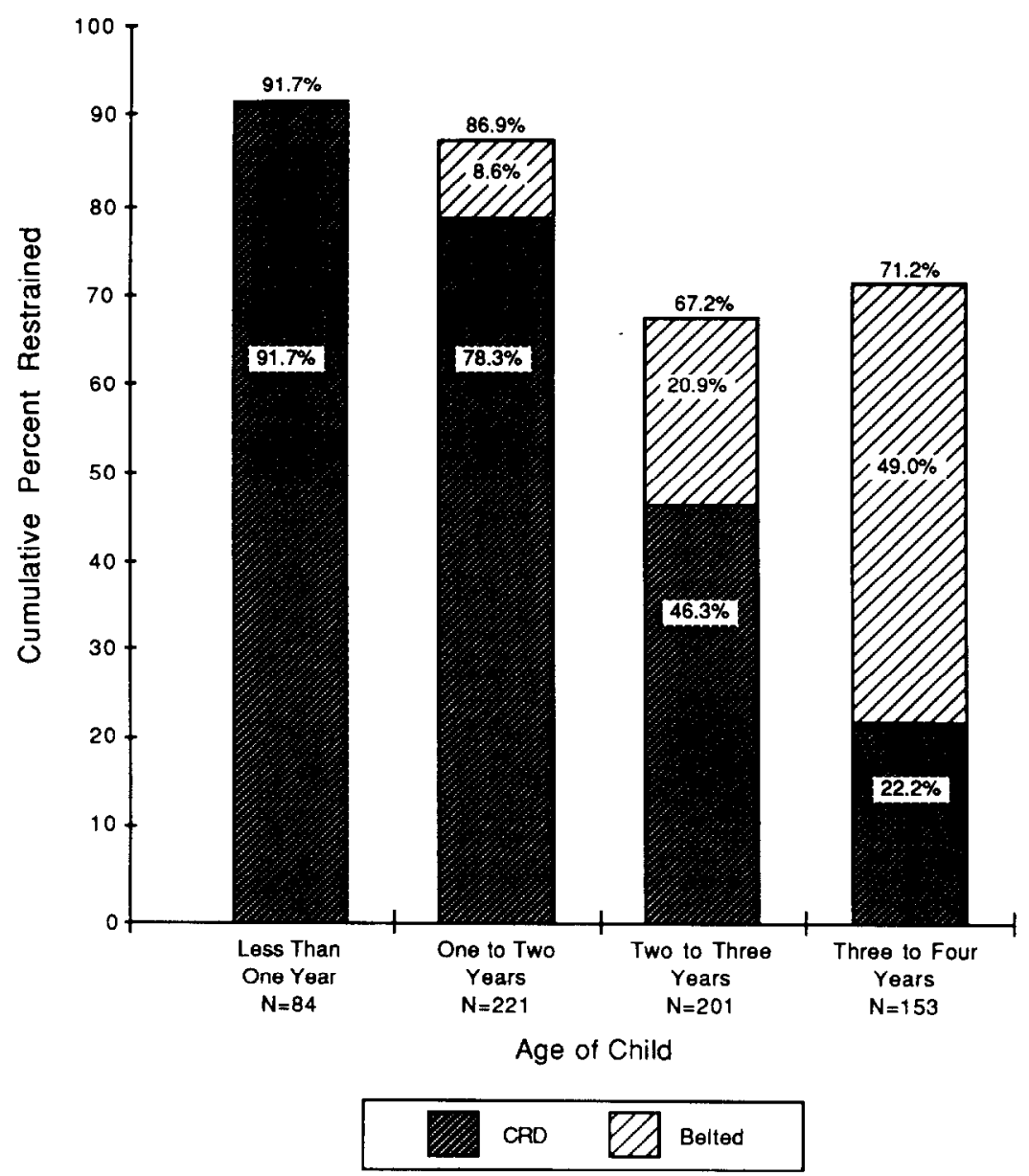

Fig. 1. Child restraint use by age of child.

In the current study, we examined the association between characteristics of motorists traveling with young children and CRD or seat belt use. Specific objectives included: (1) the measurement of current child restraint use rates, (2) examination of possible mechanisms for substantial increases in child restraint use following implementation of compulsory use laws in recent years, (3) identification of target groups for additional efforts to increase the protection of children, and (4) identification of potentially fruitful avenues for continuing efforts to increase child restraint use.

\section{METHODS}

Actual child restraint use behavior of motorists throughout southeastern Michigan was observed, followed by personal interviews and mail-back questionnaires of the automobile drivers observed. Data were collected by two trained field staff at each site: one recorded estimated age, sex, seating position, and restraint use for occupants of automobiles containing at least one young child; the other approached drivers as they were pulling into a parking space and asked if they would agree to a brief (5-8 minute) interview. If the subjects agreed, the interview was completed and the respondents were then asked if they would be willing to fill out a questionnaire, to be mailed back at their leisure.

Fast-food restaurants were selected as the type of observation site on the basis of several criteria: (1) accurate observation of correct and incorrect child restraint use was possible, (2) sufficient numbers of children under the age of four would be present in motor vehicles, (3) observations could be made efficiently and economically, (4) on-site 


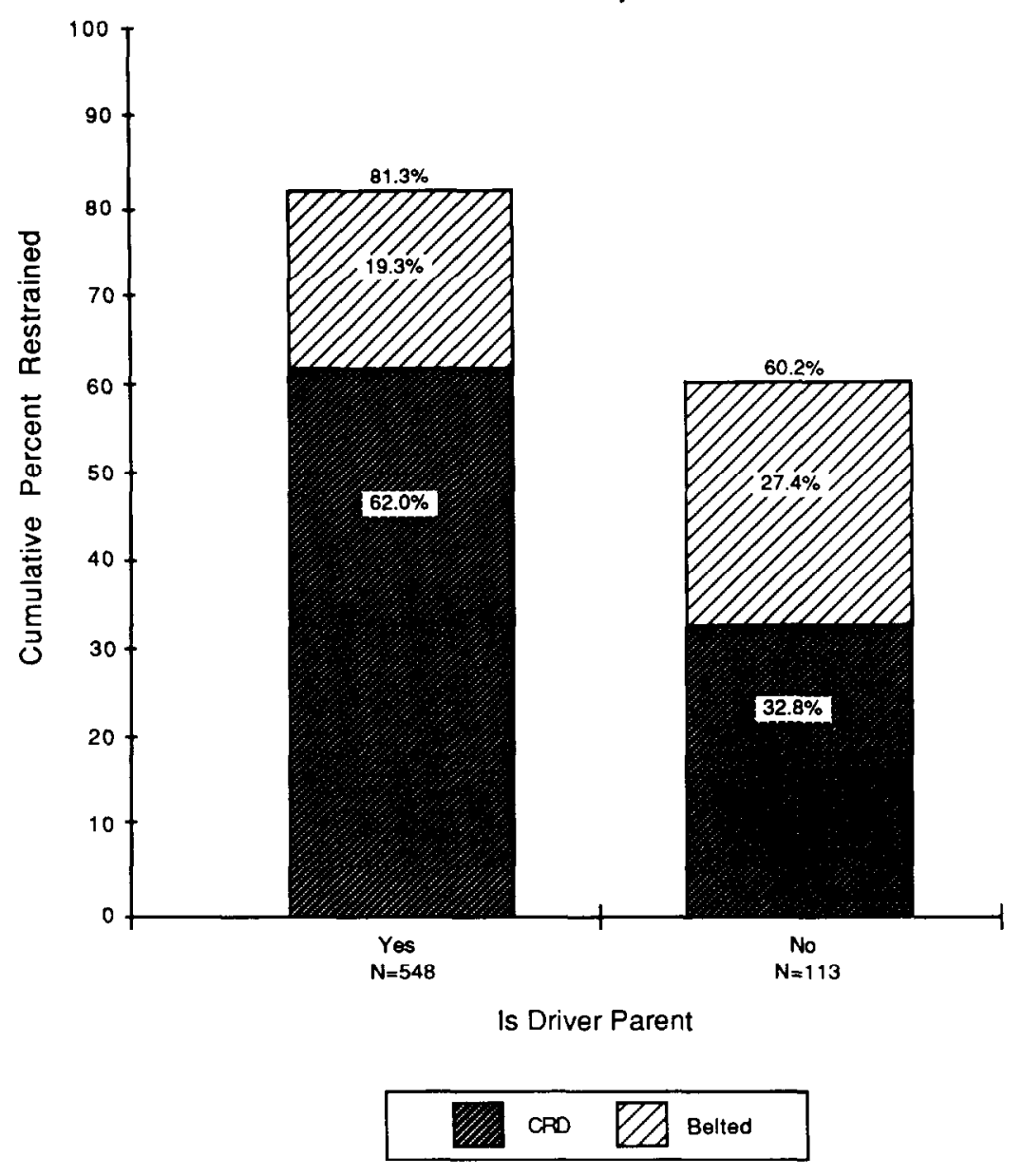

Fig. 2. Child restraint use by relationship of driver to child.

interviews with motorists could be conducted, (5) motorists observed with young children were reasonably representative of the entire population of such motorists, and (6) high proportions of motorists at the sclected sitcs would agree to participate in the survey. Several types of sites were considered, including fast-food restaurants, shopping centers, pediatric clinics, and day care centers. Motorists at pediatric clinics and day care centers were judged to be less representative of the general population than motorists at other sites. After extensive field testing of data collection protocols at alternative types of observation sites, fast-food restaurants were selected as a reasonable balance bctween competing sampling and measurement considerations. Observations and interviews were conducted during daylight hours at the entrances of 45 restaurants throughout the south'zastern region of the state in the fall of 1985 and spring of 1986.*

A total of 717 drivers traveling with young children were in the sample, consisting of cars and light trucks with young children entering the parking lots from 11 AM to 7 ?M, Sunday through Saturday. While our objective was to include all vehicles with young children, a small number of vehicles entering while an interview was in progress may vave been missed. Vehicle size, restraint use, sex, estimated age, seating position, and 16 dimensions of child restraint use were observed for all 717 cases. Of the $717,7.8 \%$ refused to participate in the study, resulting in 661 valid interviews. Of the 661 valid nterview respondents, 657 agreed to complete the follow-up questionnaire. Of the 657 distributed questionnaires, 451 were returned. The return rate for the distributed questionnaires was therefore $68.6 \%$. Additional details concerning the field methods can be found in Wagenaar, Molnar, and Businski et al. [1986].

"Communities included in the study were Ann Arbor, Brighton, Canton, Centerline, Chelsea, East Detroit, Farmington, Flint, Howell, Livonia, Madison Heights, Port Huron, Roseville, and Warren. 

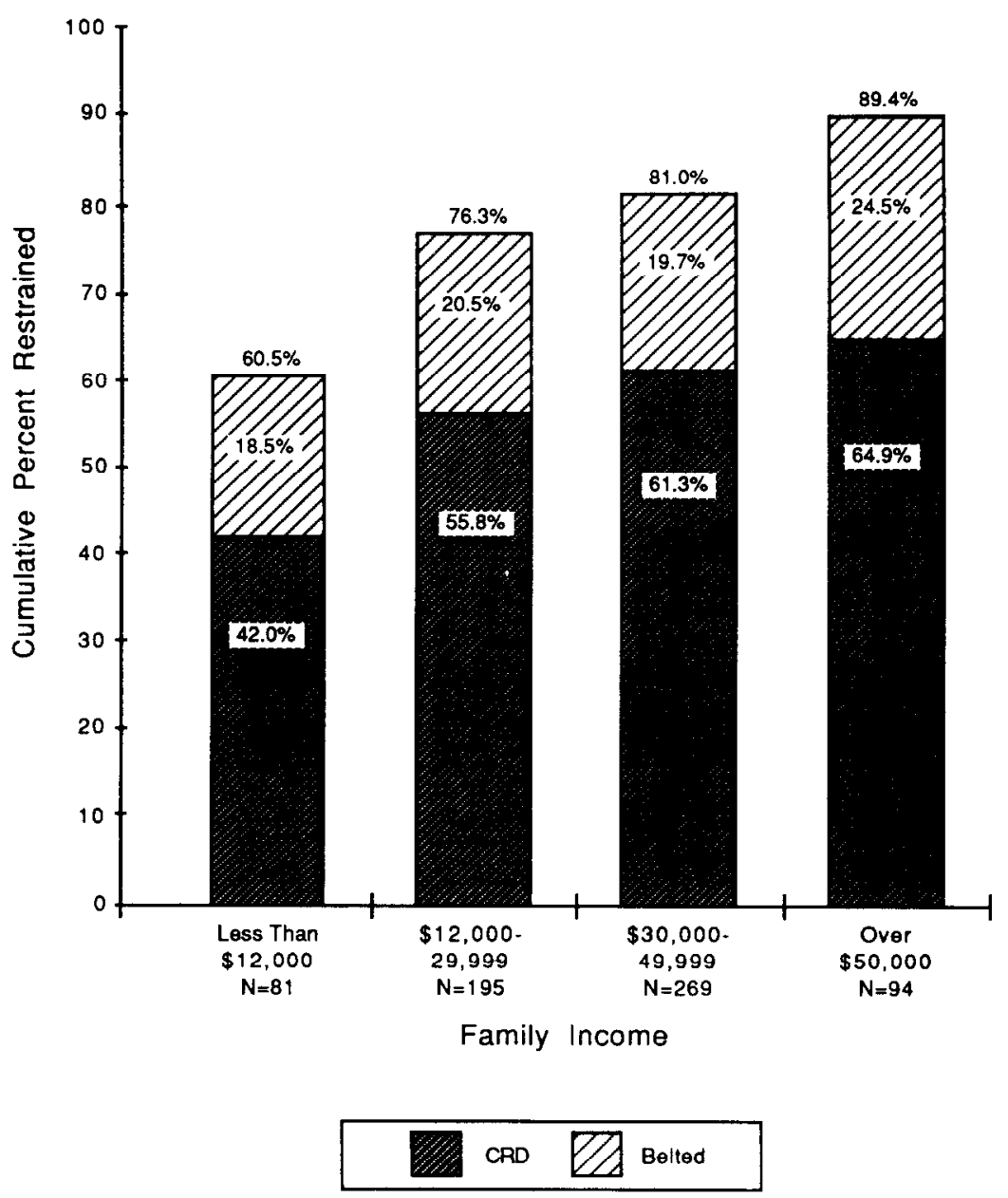

Fig. 3. Child restraint use by family income.

The final study sample was fairly representative of the larger Michigan population. First, although there was considerable variance in restraint use across sites (ranging from $42.1 \%$ to $100 \%$ ), the overall rate of child restraint use observed at these southeastern Michigan restaurants was comparable to use rates observed among children three years of age and younger in recent statewide seat belt surveys using a probability sample of 240 intersections throughout the state. In the current restaurant sample, $75 \%$ of children under four were restrained (either in seat belts or child safety seats) compared to $73.3 \%$ in both the April and July 1986 statewide seat belt survey waves and $59.1 \%$ in the December 1985 wave [Wagenaar, Molnar, and Businski et al., 1986; Wagenaar, Businski, and Molnar, 1986]. Second, the driver restraint use rate of $61.1 \%$ observed in the current study was similar to the rate among drivers of vehicles in which children under agc four were riding in the July 1986 statewide seat belt survey wave (57.7\%) and slightly higher than rates observed in the April 1986 and December 1985 statewide waves $(49.9 \%$ and $41 \%$, respectively). Third, the study sample was better educated than the general Michigan population; for example, $91.5 \%$ of the study sample had completed 12 or more years of schooling compared to $64.5 \%$ of Michigan residents age 15 and older (based on 1980 census figures). Finally, in terms of ethnic background, whites were slightly overrepresented in the study $(91.5 \%$ in our sample compared to $85 \%$ in the general Michigan population in 1980).

Percentage estimates reported below are followed by the value of two standard errors for that particular estimate. These values, when added and subtracted from the point estimates, provide $95 \%$ confidence intervals for each estimate. All standard errors 


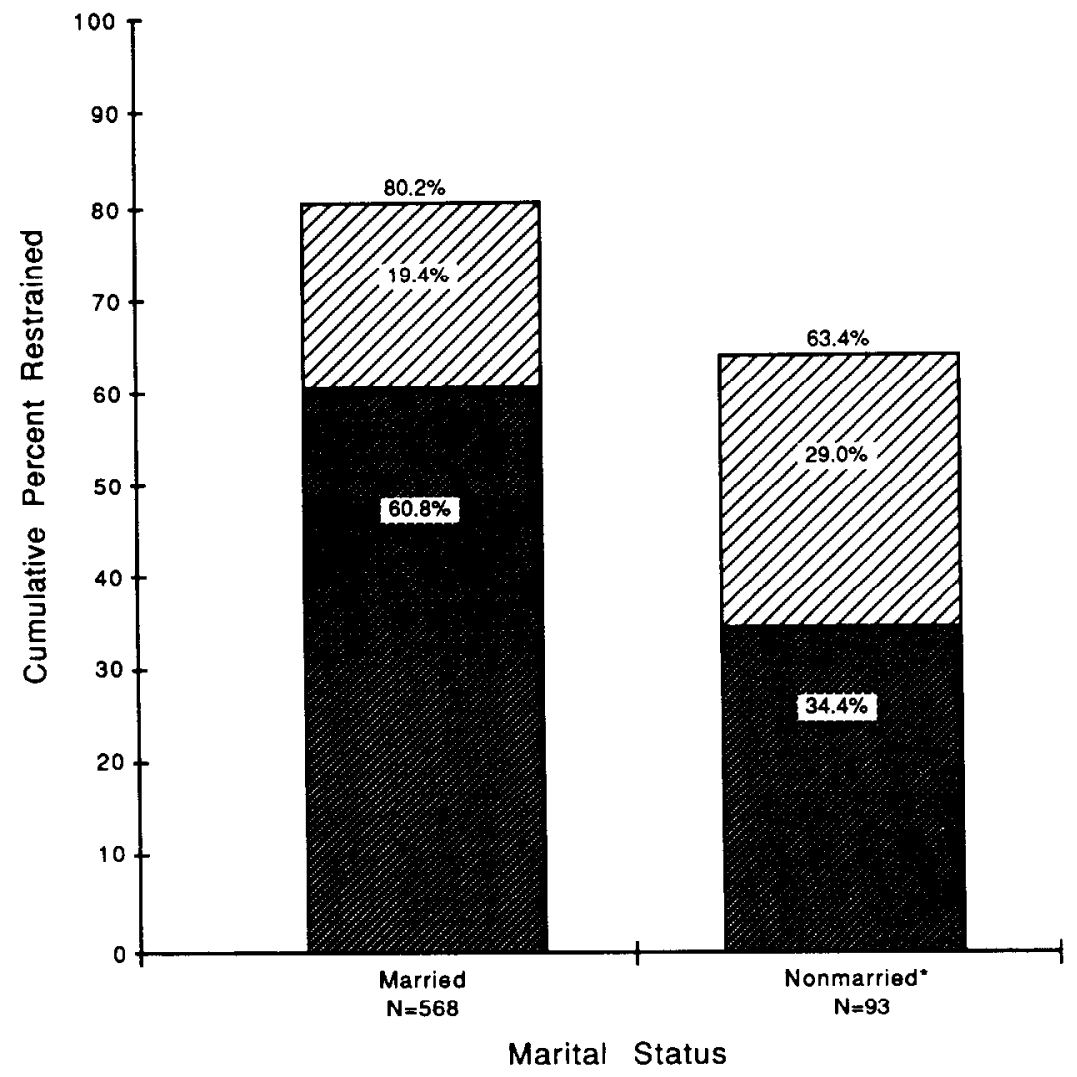

"Includes single, divorced, separated, and widowed

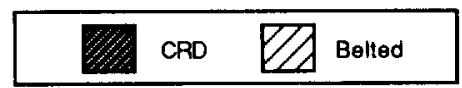

Fig. 4. Child restraint use by marital status.

were calculated using the conventional simple random sample formula: $\sigma=p q / N$. Because the majority of variables examined were nominal scale, the statistical significance of observed relationships was assessed using the $\chi^{2}$ statistic. The strength or magnitude of the statistically significant relationships was measured using Cramer's $\phi$ statistic: $\phi=\chi^{2} /\left(N^{*}(q-1)\right)$ where $q=\min (R, C)$, the minimum of the number of rows and number of columns in the table. Cramer's $\phi$ provides a measure of the strength of the association for nominal-scale variables that is roughly analogous to Pearson's $r$ for interval-scale variables [Marascuilo and McSweeney, 1977]. Finally, note that the dependent variable used in calculation of the $\chi^{2}$ and $\phi$ statistics was trichotomized child restraint use (i.e., unrestrained, in an adult seat belt, or in a child safety seat).

\section{RESULTS}

Personal and behavioral characteristics associated with restraint use

Ninety-two percent $( \pm 6 \%)$ of motorists traveling with children under the age of one had those children restrained in an approved child restraint device. Of children age 1 through $3,55 \pm 4 \%$ were traveling in a child safety seat, and an additional $20 \pm 3 \%$ were restrained with an adult seat belt. Public support for the law requiring restraint of young children was found to be very high, with $90 \pm 3 \%$ indicating agreement with a statement on the questionnaire that use of child safety seats should be required by law.*

*These sample estimates may be slightly higher than true population values, because subjects who refused to be interviewed were probably less interested in child safety issues and therefore less supportive of compulsory use. 


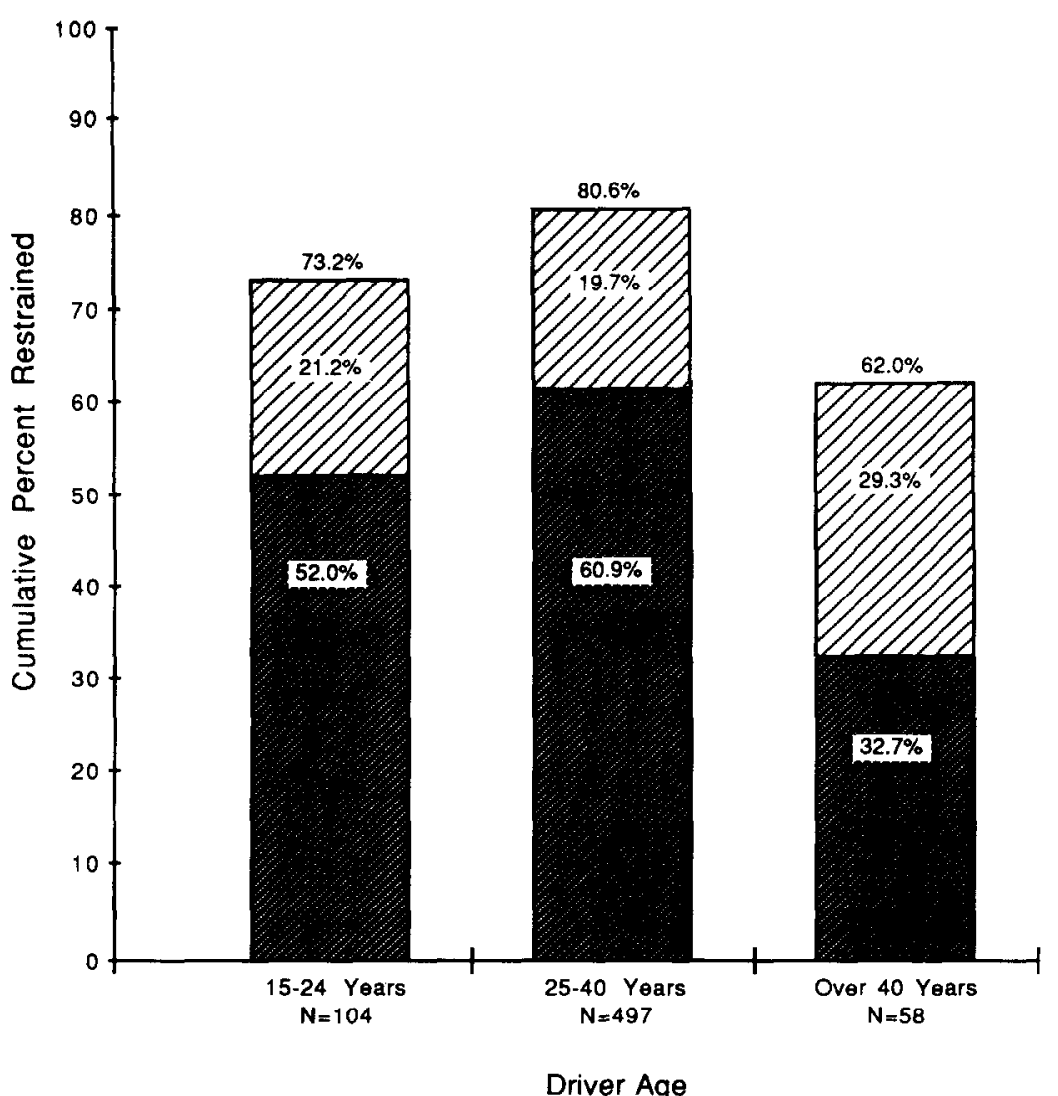

Driver Age

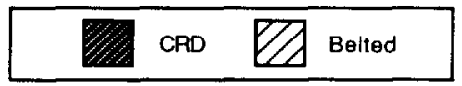

Fig. 5. Child restraint use by age of driver.

Interestingly, of those who did not agree that use of child safety seats should be required by law, the majority still restrained their children.

Results indicate that there were several groups of motorists who had significantly lower than average child restraint use rates. First, use of child safety seats decreased rapidly with reported age of child-only $22 \%$ of three-year-olds compared to $92 \%$ of infants under one year old were observed using safety seats (Fig. $1 ; \chi^{2}=192.86, d f=$ $6, p<.01 ; \phi=.38$ ). Second, drivers who reported in the interview that they were not the parents of children they were traveling with had low rates of child restraint use (Fig. $2 ; \chi^{2}=36.01, d f=2, p<.01 ; \phi=.23$ ). Third, motorists who reported incomes under $\$ 12,000$ per year in the interview showed particularly low rates of child restraint use (Fig. $3 ; \chi^{2}=24.32, d f=6, p<.01 ; \phi=.14$ ). Those with incomes of $\$ 12,000$ to $\$ 30,000$ per year were also found to have substantially lower rates of use than those with incomes over $\$ 30,000$.

Other groups with low child restraint use include drivers who identified themselves as unmarried in the interview (Fig. $4 ; \chi^{2}=24.98, d f=6, p<.01 ; \phi=.14$ ), drivers who identified themselves as over the age of 40 in the interview (Fig. $5 ; \chi^{2}=19.51$, $d f=4, p<.02 ; \phi=.12$ ), and drivers observed with four or more passengers (Fig. 6; $\chi^{2}=21.66, d f=6, p<.01 ; \phi=.12$ ). Lower than average child restraint use among unmarried drivers and drivers over the age of 40 was seen both for those with family incomes of $\$ 12,000$ to $\$ 29,999$ and those with incomes of $\$ 30,000$ and over (Table 1). For those with a family income less than $\$ 12,000$, differences could not be discerned because of the small number of cases. The relationship between age of driver and child restraint use was also examined while controlling for the relationship between driver 

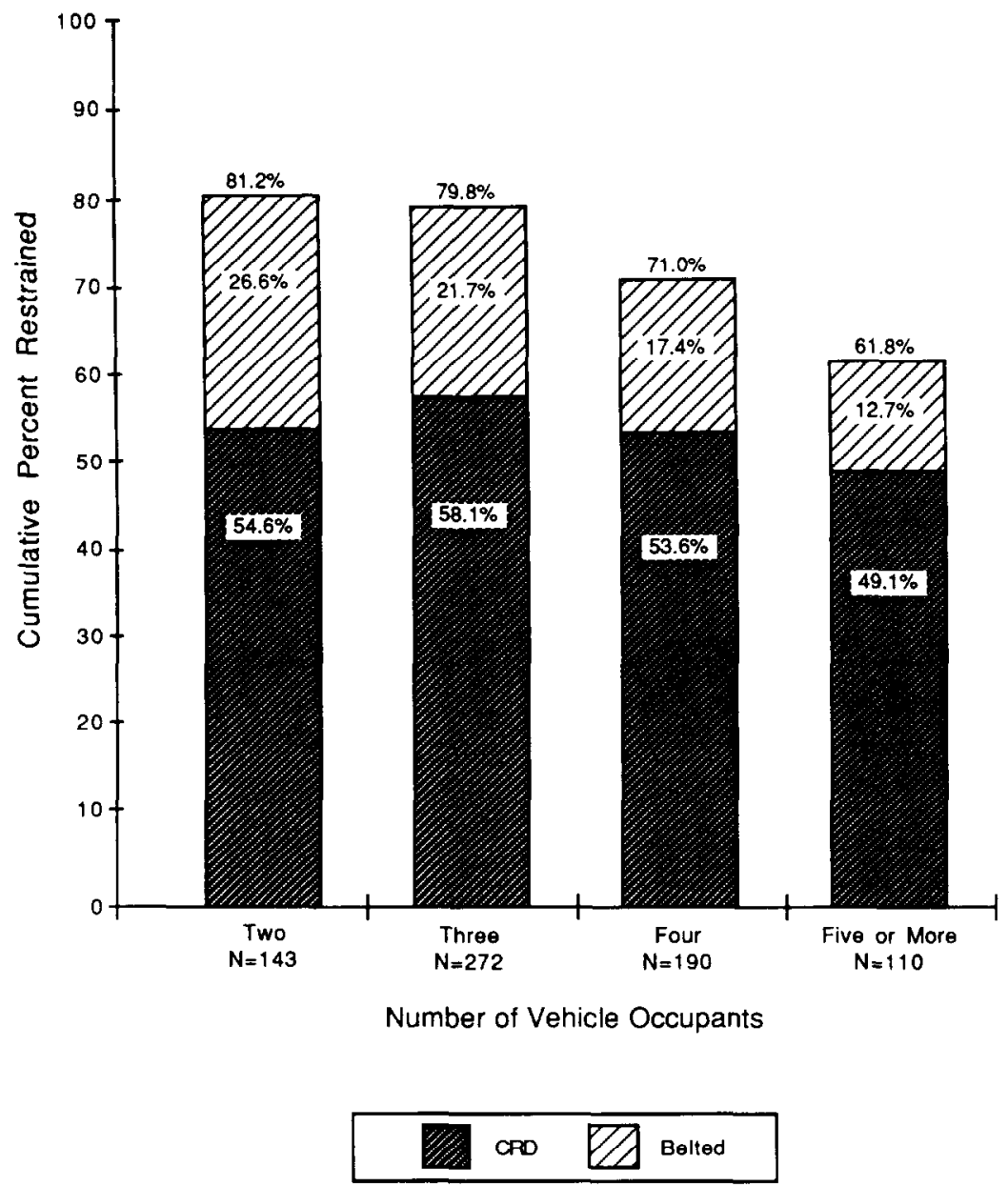

Fig. 6. Child restraint use by number of vehicle occupants.

and child (parent vs. nomparent). Differences were nonsignificant, however, due to the small number of cases within each subcategory (Table 2).

Motorists who identified themselves as nonwhite in the interview were another group with low rates of seat belt or CRD use (Fig. $7 ; \chi^{2}=39.72, d f=2, p<.01 ; \phi=.24$ ). Differences in child restraint use between whites and nonwhites remained after controlling for the effects of income (Table 1). Because few studies of the effect of race on child restraint use have controlled for income, this finding is of particular interest.

Drivers who reported in the interview that they travel with young children one or fewer days per week also had much lower rates of restraint use than other drivers $\left(x^{2}=23.87, d f=12, p<.05 ; \phi=.14\right)$. This pattern was consistent across all income groups (Table 1), and was also evident when looking at parents and nonparents separately (Table 2).

Finally, observed belt use by the driver was strongly related to observed use of safety seats or seat belts for children (Fig. $8 ; \chi^{2}=127.38, d f=2, p<.01 ; \phi=.43$ ). As a result, continued efforts to increase the proportion of adults using seat belts following enactment of adult compulsory use laws (which have now passed in 27 states and the District of Columbia) may have spillover effects in increasing restraint use for children.

\section{Relationship between perceptions of the law and restraint use}

All but two respondents completing the questionnaire believed that CRDs are effective in reducing risk of a crash fatality, and almost everyone interviewed $(95 \pm 2 \%)$ reported awareness of the mandatory child restraint law. However, the majority of 


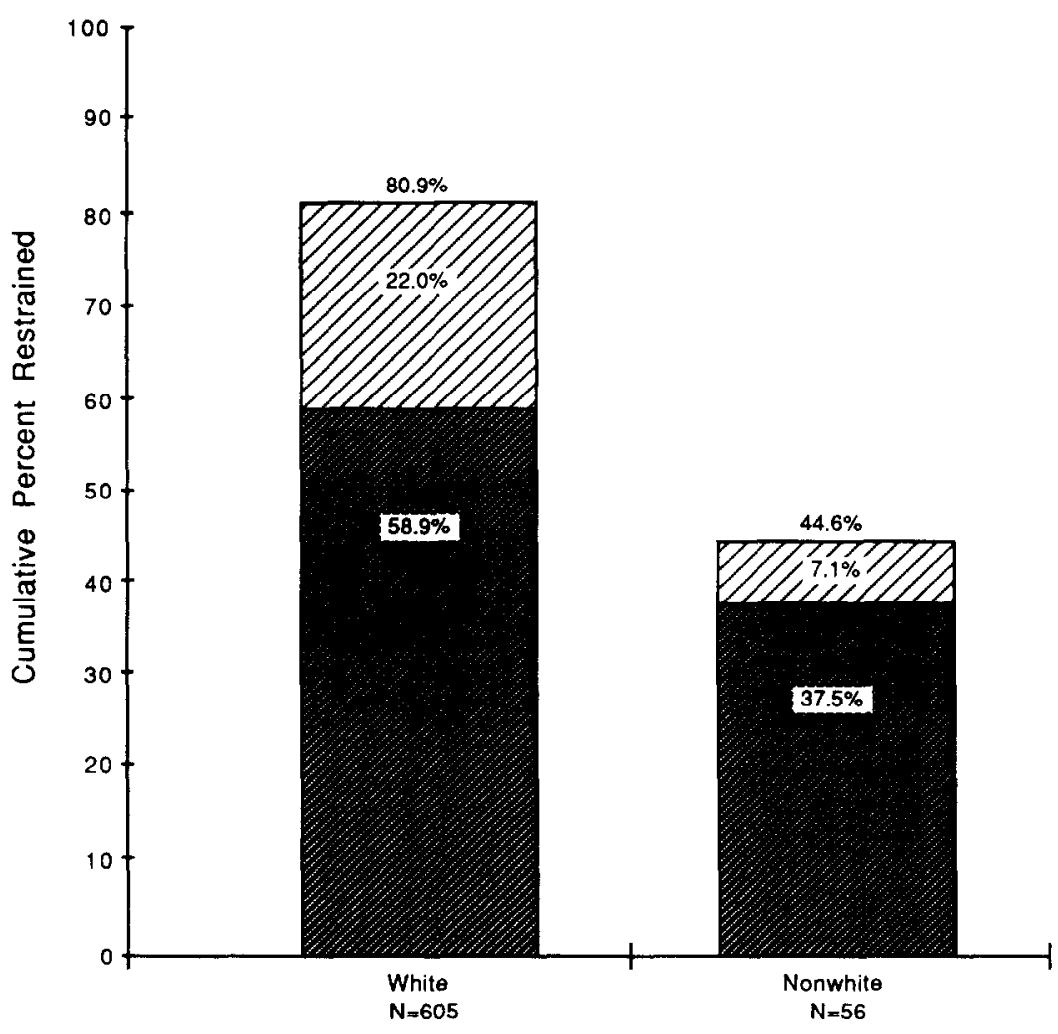

Ethnic Background

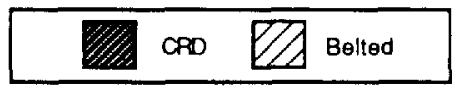

Fig. 7. Child restraint use by ethnic background.

interviewees $(90 \pm 2 \%)$ did not know the specifics of the law's requirements (i.e., that an infant under age one must be in a safety seat in any seat position, that those age one through three may be in a seat belt if in the rear seat). Those who did not know the specific requirements of the law had lower rates of seat belt and safety seat use.

Interviewees clearly believed that the child restraint law is not enforced. Seventyfive percent $( \pm 3 \%)$ believe that police rarely or never stop violators of the child restraint law. Furthermore, even if one experiences the rare event of a police stop, $38 \pm 4 \%$ accurately believed that a ticket is rarely or never issued. For example, in 1986 in Michigan, only 1,056 citations were issued by state police for violations of the child restraint law compared to nearly 5,000 in Tennessee in 1983, a state half the size of Michigan [Decker, Dewey, and Hutcheson et al., 1984]. Combining the perceived probability of being stopped with the perceived probability of receiving a ticket once stopped shows that motorists believe there is very little chance of experiencing any enforcement penalty for violation of the law. Motorists also seemed to be dissatisfied with the low levels of enforcement $-91 \pm 3 \%$ agreed with a questionnaire item that child restraint laws should be strictly enforced $(67 \pm 4 \%$ of all respondents completing the questionnaire item reported strong agreement).

Very low levels of perceived enforcement risk yet high rates of child restraint use indicate that enforcement has not been a major influence on use. In fact, almost half $(49 \pm 4 \%)$ of the motorists interviewed said that fear of receiving a ticket does not influence their child restraint use. Instead of a simple deterrence effect, the law and associated programmatic efforts appear to have achieved a significant change in social norms concerning safety restraints for young children. Three-quarters $(78 \pm 3 \%)$ of the 
Table 1. Percent of children restrained by family income and marital status, age of driver, ethnic background, and days traveling with children per week*

Family income

\begin{tabular}{|c|c|c|c|c|}
\hline \multicolumn{5}{|c|}{ Family Income } \\
\hline & Less than $\$ 12,000$ & $\$ 12,000-\$ 29,999$ & $\$ 30,000$ and over & TOTAL \\
\hline \multicolumn{5}{|l|}{ Marital Status } \\
\hline Nonmarried & $61.9 \pm 15.0$ & $65.5 \pm 17.7$ & $73.7 \pm 20.2$ & $63.4 \pm 10.0$ \\
\hline Married & $59.0 \pm 15.8$ & $78.3 \pm 6.4$ & $83.7 \pm 4.0$ & $80.2 \pm 3.3$ \\
\hline \multicolumn{5}{|l|}{ Age of Driver } \\
\hline $15-24$ & $64.7 \pm 16.4$ & $73.0 \pm 14.6$ & $90.0 \pm 11.0$ & $73.2 \pm 8.7$ \\
\hline $25-40$ & $56.1 \pm 15.5$ & $81.3 \pm 6.6$ & $84.1 \pm 4.2$ & $80.6 \pm 3.5$ \\
\hline Over 40 & $66.7 \pm 38.5$ & $47.4 \pm 22.9$ & $67.7 \pm 16.8$ & $62.0 \pm 12.7$ \\
\hline \multicolumn{5}{|c|}{ Ethnic Background } \\
\hline White & $67.7 \pm 11.6$ & $79.7 \pm 6.0$ & $84.5 \pm 3.9$ & $80.9 \pm 3.2$ \\
\hline Nonwhite & $31.2 \pm 23.2$ & $44.4 \pm 23.4$ & $60.0 \pm 21.9$ & $44.6 \pm 13.3$ \\
\hline \multicolumn{5}{|c|}{$\begin{array}{l}\text { Days Traveling } \\
\text { with Children }\end{array}$} \\
\hline 1 or Less & $31.2 \pm 23.2$ & $59.3 \pm 18.9$ & $54.8 \pm 17.9$ & $49.4 \pm 11.4$ \\
\hline 2 or More & $68.7 \pm 11.6$ & $79.2 \pm 6.3$ & $85.8 \pm 3.8$ & $81.6 \pm 3.2$ \\
\hline TOTAL & $60.5 \pm 10.9$ & $76.4 \pm 6.1$ & $83.2 \pm 3.9$ & $77.8 \pm 3.2$ \\
\hline
\end{tabular}

\footnotetext{
${ }^{*}$ Values are an estimated percent of children restrained followed by twice the standard error of
} the estimate, which when added to and subtracted from the estimate produce $95 \%$ confidence intervals.

respondents believe that $60 \%$ or more of the public support the law. Over half $(52 \pm$ $4 \%$ ) believe $60 \%$ or more of the public obeys the law. Almost two-thirds (64 $\pm 5 \%$ ) report that more than $80 \%$ of their friends restrain children when driving. Almost threequarters $(72 \pm 4 \%)$ believe other people notice whether young children are belted or in a safety seat. All of these items indicate that there has now emerged a social norm that drivers are expected to restrain young children when traveling in an automobile. Furthermore, respondents who believe that the public obeys the law, that their friends use child restraints, and that others notice use are more likely to use child restraints themselves.

\section{Relationship between restraint characteristics and restraint use}

Although only a quarter of the respondents completing the questionnaire believed that children do not like to travel in safety seats $(24 \pm 4 \%)$, those who felt this way were substantially less likely to use CRDs. Continuing education efforts stating that children enjoy traveling in CRDs may help increase use by this part of the population.

Respondents who indicated no strong opinion on the questionnaire concerning whether CRD use is bothersome and whether CRD use should be required by law had significantly lower rates of child restraint use than those who had strong opinions on these issues (either positive or negative). This pattern may indicate that there is a small segment of the population that is apathetic concerning child restraints. Perhaps they do not take child restraint use seriously and are not willing to invest time and energy in this issue.

\section{DISCUSSION}

Our findings suggest two sets of strategies to increase child restraint device use rates. The first set of strategies involves knowledge of the mandatory use law. Despite overwhelming support for the law, the level of knowledge about specifics of the law was low. Furthermore, respondents who did not know the specifics of the law had lower rates of child restraint use. Continuing efforts to educate parents about the child restraint law by safety officials and others having regular contact with children (such as health care 

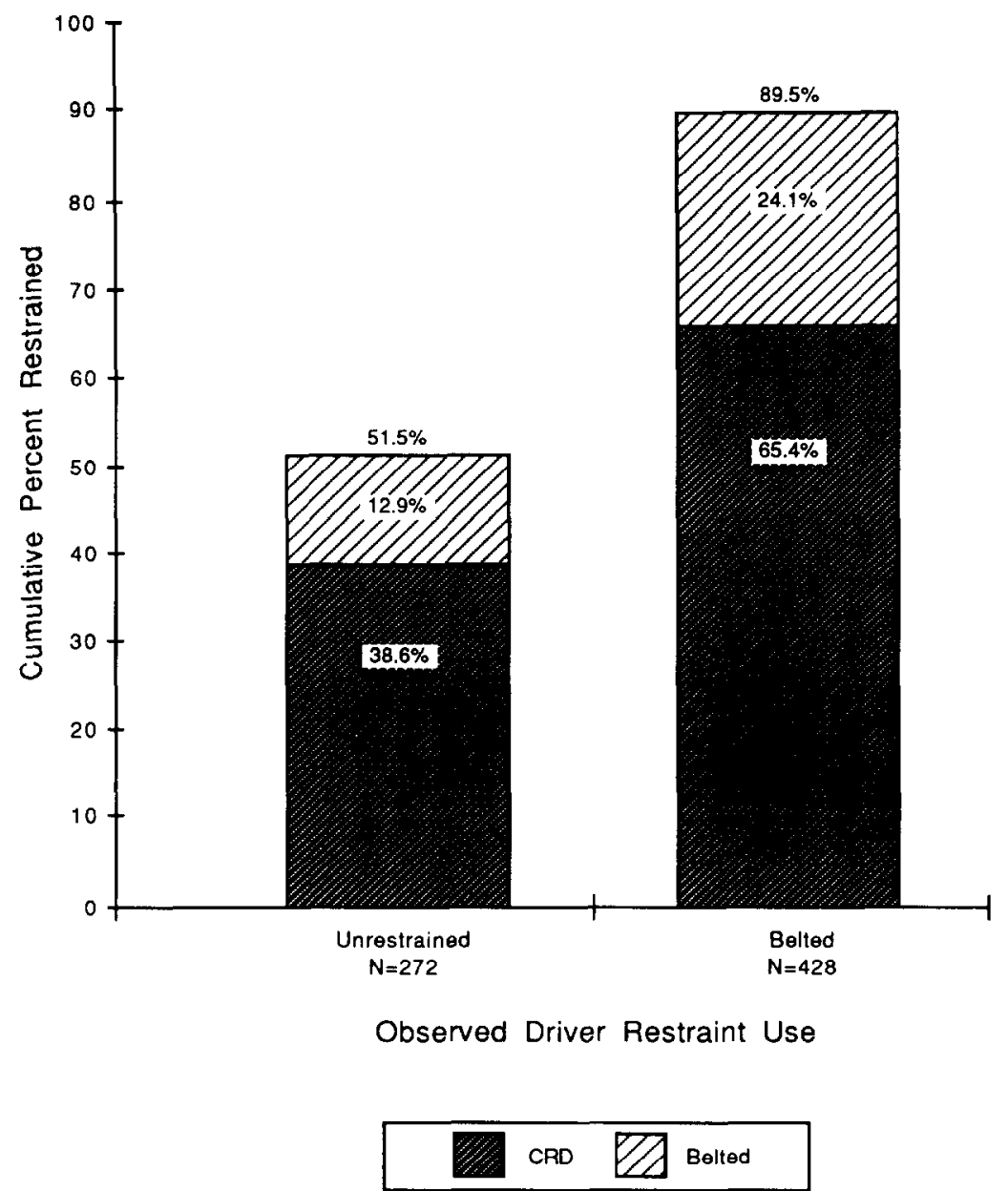

Fig. 8. Child restraint use by observed driver restraint use.

providers and day care providers) are warranted. This education should include reassurance that children not only become accustomed to CRDs with regular use but actually prefer to ride in them.

The second set of strategies involves enforcement of the law. Currently the restraint law is not strictly enforced. This practice was accurately reflected in the respondents' perceptions that police rarely stop or ticket violators of the CRD law. Since fear of enforcement does not seem to be motivating appropriate CRD use at this point, increased enforcement efforts-to the point where it becomes obvious to the motoring public that traffic officials take the law seriously-may be indicated. Stated alternatively, the law seems to have had an indirect educational, symbolic, and normative effect, but its direct motivational effect has yet to be activated or tested. Although limited resources may preclude the police from cnhancing their enforcement cfforts, evidence from other studics suggests that such efforts do increase use rates [Williams, Preusser, and Blomberg et al., 1987].

In addition to directly influencing use, stricter enforcement would probably add impetus to what is apparently a growing public norm that child restraint use is the expected behavior. Respondents believed that most of their friends used CRDs, that the public in general obeys the law, that others notice when CRDs are not used, and that the law should be strictly enforced. Public information campaigns should build upon this developing norm. Such efforts would be similar to drinking and driving efforts which appear to be more successful when they emphasize the changing norms about acceptable drinking behavior than when they simply admonish the public not to drink and drive [Wagenaar, 1983]. 
Table 2. Percent of children restrained by relationship of driver to child and age of driver and days traveling with children per week*

Relationship of Driver to Child

Parent

Age of Driver

15-24

$25-40$

Over 40

Days Traveling

with Children
$80.3 \pm 9.4$

$82.1 \pm 3.6$

$70.6 \pm 22.1$

1 or Less

2 or More
$52.8 \pm 16.6$

$83.5 \pm 3.3$

$81.5 \pm 3.3$
$57.6 \pm 17.2$

$64.1 \pm 15.4$

$58.5 \pm 15.4$

$46.3 \pm 15.6$

$68.1 \pm 11.0$

$60.2 \pm 9.2$
TOTAL

$73.2 \pm 8.7$

$80.6 \pm 3.5$

$62.0 \pm 12.7$

$49.4 \pm 11.4$

$81.6 \pm 3.2$

TOTAL

*Values are an estimated percent of children restrained followed by twice the standard error of the estimate, which when added to and subtracted from the estimate produce $95 \%$ confidence intervals.

In addition to these sets of strategies, our findings suggest that efforts to increase child restraint use should be especially directed at certain groups at high risk for nonuse. Consistent with previous reports, drivers of low income, other than white race, and over 40 years of age had lower CRD use rates.

Finally, our analyses indicate the need for studies of CRD use combining observation and interview methods which include much larger numbers of respondents. Any study focusing on drivers traveling with small children will necessarily overrepresent married female 20-40-year-old parents. These characteristics, with the exception of driver gender, were found in the current study to be associated with CRD use. Multivariate analyses in our study were limited by the small number of cases within each subcategory, and the resulting large standard errors associated with subgroup CRD use estimates. The resources required for larger-scale field observation and interview studies are a significant impediment, but major further advances in knowledge of restraint behavior among motorists traveling with children are not likely without such efforts.

In summary, although a high proportion of drivers restrain young children in automobiles, unacceptable numbers of children are still at risk as motor vehicle occupants. Increased educational efforts about the law and enhanced enforcement of the law would further reduce this major risk to the health and well-being of children.

Acknowledgments - This research was supported by the Michigan Office of Highway Safety Planning and the U.S. National Highway Traffic Safety Administration. Findings and conclusions, however, remain solely the authors'. The assistance of Karen L. Businski with field data collection is gratefully acknowledged.

\section{REFERENCES}

Decker M. D., Dewey M. J., Hutcheson R. H. and Schaffner W., The use and efficacy of child restraint devices. JAMA 252(18):2571-2575, 1984.

Evans L., The effectiveness of safety belts in preventing fatalities. Accid. Anal. Prev. 18(3):229-241, 1986.

Evans L. and Frick M. C., Safety belt effectiveness in preventing driver fatalities versus a number of vehicular, accident, roadway, and environmental factors. J. Saf. Res. 17:143-154, 1986.

Faber M. M. and Hoppe S. E., Correlates of seat belt use in new parents. Q.J. 6(4):19-29, 1984.

Foss R. D., Psychosocial factors in child safety restraint use. J. Appl. Soc. Psych. 15(3):269-284, 1985.

Hletko P. J., Hletko J. D. and Shelness A. M. et al., Demographic predictions of infant car seat use. Am J. Dis. Child. 137(11): 1061-1063, 1983. 
Jonah B. A. and Dawson N. E., The national vehicle occupant restraint survey: Attitudes toward and use of restraints by Canadians. Ottawa, Ontario, Canada: Road and Motor Vehicle Traffic Safety Branch, Transport Canada. March 1982.

Kielhorn T. G. and Westphal J., A study of the use and non-use of child restraint devices in metropolitan Oklahoma. Oklahoma City, OK: Oklahoma Survey Consultants, Oklahoma Highway Safety Office, 1980.

Marascuilo L. A. and McSweeney M., Nonparametric and Distribution-Free Methods for the Social Sciences. Monterey, CA: Brooks/Cole Publishing Co., 1977.

Neumann C. G., Neumann A. K. and Cockrell M. E. et al., Factors associated with child use of automobile restraining devices. Am. J. Dis. Child. 128:469-474, 1974.

Philpot J. W., Heathington K. W. and Perry R. L. et al., Use of child-passenger safety devices in Tennessee. Trans. Res. Rec. 739:8-14, 1979.

Pless I. B. and Roghmann K. J., Safety restraints for children in automobiles: Who uses them? Can. J. Pub. Hith. 69:289-292, 1978.

Rood D. H. and Kraichy P. P., Evaluation of New York State's mandatory occupant restraint law: Volume III, observational surveys of safety restraint use by children in New York State. Institute of Traffic Safety Management and Research, State University of New York at Albany. U.S. Department of Transportation, National Highway Traffic Safety Administration Report No. [DOT HS-806-972], Springfield, VA: National Technical Information Service, 1986.

Rutherford W. H., Greenfield T. and Hayes H. R. M. et al., The medical effects of seat belt legislation in the United Kingdom. London, England: Great Britain Department of Health and Social Security, 1985.

Verreault R., Stulginskas J. and Keyl P. et al., Use of automobile seat restraints by children in two Canadian cities. Can. Med. Assoc. J. 126:1163-1168, 1982.

Wagenaar A. C., Drinking and driving: New directions. J. Psych. Treat. Eval. 5:539-544, 1983.

Wagenaar A. C. and Webster D., Preventing injuries to children through compulsory automobile safety seat use. Ped 78(4):662-672, 1986.

Wagenaar A. C. and Wiviott M. B. T., Effects of mandating seatbelt use: A series of surveys on compliance in Michigan. Pub. Hlth. Rep. 101(5):505-513, 1986.

Wagenaar A. C., Wiviott M. B. T. and Businski K. L., Direct observation of seat belt use in Michigan: December 1985. Ann Arbor, MI: University of Michigan Transportation Research Institute, 1986.

Wagenaar A. C., Businski K. L. and Molnar L. J., Direct observation of seat belt use in Michigan: July 1986. Ann Arbor, MI: University of Michigan Transportation Research Institute, 1986.

Wagenaar A. C., Molnar L. J., Businski K. L. and Margolis L. H., Correlates of child restraint use. Ann Arbor, MI: University of Michigan Transportation Research Institute, 1986.

Ward W. B. and Clearie D., 1982 child safety seat utilization survey final report. South Carolina: Office of Health Education, South Carolina Department of Health and Environment Control, December 1982.

Williams A. F., Factors associated with scat belt usc in familics. J. Saf. Res. 4:133-138, 1972.

Williams A. F., Preusser D. F., Blomberg R. D. and Lund A. K., Results of a seat belt use law enforcement and publicity campaign in Elmira, New York. Accid. Anal. Prev. 19(4):243-249, 1987. 